\title{
CNN-Bidirectional LSTM Based Optical Character Recognition of Sanskrit Manuscripts : A Comprehensive Systematic Literature Review Bhavesh Kataria ${ }^{*}$, Dr. Harikrishna B. Jethva ${ }^{2}$
}

${ }^{1}$ Research Scholar, Gujarat Technological University, Ahmedabad, Gujarat, India

${ }^{2}$ Associate Professor, Department of Computer Engineering, Government Engineering College, Patan, Gujarat, India

Corresponding Author* : bhavesh.iisc@gmail.com

\begin{abstract}
Optical character recognition (OCR) is a technology that allows you to convert different types of documents or images into searchable, editable, and analyzable data. The current work on Sanskrit Character Recognition from Images of Text Documents is one of the most difficult due to similarities in the forms of unique letters, script complexity, non-forte in the representation, and a vast number of symbols. The Devanagari script is used to write the Sanskrit language. There are a variety of approaches for recognizing characters in a scanned image. The present research initiatives highlight the importance and needs of efforts in recognition of printed and handwritten documents written in Sanskrit language. This paper is aims at reviewing the state of various scripts in use including those from medieval to present era and explores the prospective of digital recognition of printed texts and thereby pointing towards futuristic trends in developing restoration software for Sanskrit scripts. Challenge is due to the number of languages and their diverse scripts. The scarcity of digitized linguistic resources makes the task a tougher one. The paper also highlights on the characteristics and challenges of recognition of scripts of Sanskrit origin. Largely the digital recognition is limited to simple numerals and isolated characters. In addition, this review article serves the purpose an optical character recognition (OCR) system that enables to analyse the word recognition and translate various types of Sanskrit documents or images into text using deep learning architectures which include Convolutional Neural Network (CNN) and Bidirectional long-short term memory (Bidirectional LSTM).
\end{abstract}

Keywords : Optical Character Recognition, Convolutional Neural Network, Bidirectional LSTM, Long-Short Term Memory

\section{INTRODUCTION}

Sanskrit was used to write the majority of India's finest literary works. It is considered the mother tongue of all contemporary languages. The Vedas, which were written in sanskrit, represent the spirit of Indian culture and history. The essential ideas of Buddhism were also recorded in sanskrit. The presence of old scientific and mathematical study work published in Sanskrit is gaining prominence in many academic groups. Scientists from all across the world are devoting more and more effort to deciphering these historic research texts. Sanskrit texts also include a wealth of information about science, mathematics, Hindu mythology, Indian civilisation, and culture. However, a major barrier is 
the unavailability of correctly digitised and labelled versions of Sanskrit texts. In addition, the problem is exacerbated by inadequate maintenance and text quality. As a result, it is critical to digitise such historical texts, which are not only valuable for study but also represent a vital element of India's culture and tradition.

Current research in OCR is focusing on the effect of multi-font and multi-size text on OCR accuracy. The optical character recognition (OCR) system that enables to analyse the word recognition and translate various types of Sanskrit documents or images into text using deep learning architectures which include Convolutional Neural Network (CNN) [1][2], Recurrent Neural Networks (RNN) [], Long ShortTerm Memory (LSTM) and Bidirectional Long ShortTerm Memory (BLSTM) networks.

The growth of technology in terms of scanning equipment as well as processing power has also contributed to the advancement of in these architectures. There are several OCRs on the market now that can do character recognition like Tesseract OCR, Indsenz OCR and eAksharayan OCR, ImageNet, AlexNet, GoogLeNet, ResNet and many other [1] [15][68][69][70][71].

\section{LITERATURE SURVEY}

In current research, Support vector machines (SVMs) and artificial neural networks are examples of machine learning approaches (ANNs) [8] [9] are used to categorise characters in images in an OCR system for Indian languages. Existing Indic OCRs perform poorly on deteriorated or badly kept documents or materials, and their digitization capabilities are confined to high-quality text documents.
Optical Character Recognition for Sanskrit was reported by M. Avadesh et al. [12]. The researchers used Convolution Neural Networks and an image segmentation technique to calculate pixel intensities and identify letters in the picture. To increase segmentation accuracy, the OCR treats common compound characters (half letter combinations) as different classes.

OCR can be done offline or online. OCR converts document images to text that are printed or handwritten. Optical handwriting recognition (OHR) is a term used to describe handwriting recognition that is similar to optical character recognition (OCR). Offline data that describes printed or typewritten items is frequently interpreted using OCR [13]. OHR's purpose is to understand the contents of handwritten data and create a description of that interpretation in the format needed. Off-line handwriting recognition or online handwriting recognition are terms used to describe the OHR job [14]. Off-line handwriting recognition works using a dataset collected from a scanned handwritten document, whereas on-line handwriting recognition works with a data stream coming from a transducer while the user writes. This study on OCR of printed document images is of interest to us.

Many more studies have been conducted on the recognition of manuscripts in various Indian languages like Hindi, Gujarati, Sanskrit, Marathi, Bangla, Telugu, Tamil, Kannada, Malayalam, Oriya, Malayalam and many other [16 to 26].

Maalej et al [27] proposed Convolutional Neural Network and BLSTM for offline Arabic handwriting recognition, To automatically extract characteristics from raw photos, a Convolutional Neural Network (CNN) is used first, followed by a Bidirectional Long 
Short-Term Memory (BLSTM) and a Connectionist Temporal Classification layer (CTC). This model is tested on an expanded IFN/ENIT database that was produced using data augmentation techniques.

Rectangle Histogram Oriented Gradient (R-HOG) representation as the basis for extraction of features. These algorithms require a few simple arithmetic operations per image pixel which makes them suitable for real-time applications. [27]
Furthermore, the HMM (Hidden Markov Model) classifier did not achieve excellent recognition rates, it was used. There are many internal states in HMMs that aren't observable. As a result, every internal state of the HMM conveys just a few bits of information regarding the categorization of previous observations. Standard HMMs, on the other hand, use Gaussian mixture models, which employ Gaussians with diagonal covariance matrices and are restricted in their ability to describe the feature space of independent characteristics. [28].

Table 2 : Linguistic Composition of India and Status of OCR

\begin{tabular}{|c|c|c|c|c|}
\hline Author & Description & Title & Year/Source & Findings \\
\hline $\begin{array}{l}\text { Divakar Yadav, } \\
\text { Sonia Sánchez- } \\
\text { Cuadrado and } \\
\text { Jorge Morato } \\
\text { [29] }\end{array}$ & $\begin{array}{l}\text { Journal of } \\
\text { Information } \\
\text { Processing } \\
\text { Systems }\end{array}$ & $\begin{array}{l}\text { Optical Character } \\
\text { Recognition for Hindi } \\
\text { Language } \\
\text { Using a Neural- } \\
\text { network Approach }\end{array}$ & 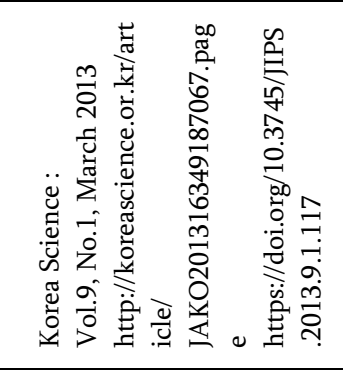 & $\begin{array}{l}\text { Worked on OCR for printed } \\
\text { Hindi text in Devanagari } \\
\text { script } \\
\text { Methods : Segmented line } \\
\text { from text block } \\
\text { Feature Extraction : Histogram } \\
\text { Classification : Artificial } \\
\text { Neural Network (ANN), }\end{array}$ \\
\hline $\begin{array}{l}\text { Agravatt, } \\
\text { Shweta and } \\
\text { Goswami, } \\
\text { Mukesh and } \\
\text { Agravatt, Hardik } \\
\text { [30] }\end{array}$ & $\begin{array}{l}\text { International } \\
\text { Journal of } \\
\text { Software \& } \\
\text { Hardware } \\
\text { Research in } \\
\text { Engineering }\end{array}$ & $\begin{array}{l}\text { A New Approach for } \\
\text { Zone Identification on } \\
\text { Printed Gujarati Text: } \\
\text { Vertical Bar Method }\end{array}$ & 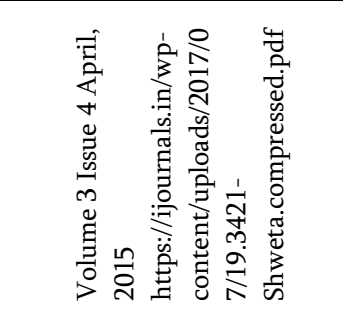 & $\begin{array}{l}\text { Worked on Gujarati language : } \\
\text { Aryan family splitted in to } \\
\text { Upper Zone, Middle Zone and } \\
\text { Lower Zone } \\
\text { Methods : Zone Boundary } \\
\text { dentification } \\
\text { No Calcification Performed }\end{array}$ \\
\hline $\begin{array}{l}\text { K. R.Dahake, S. } \\
\text { R. Suralkar, and } \\
\text { S. P. Ramteke } \\
\text { [31] }\end{array}$ & $\begin{array}{l}\text { International } \\
\text { Journal of } \\
\text { Computer } \\
\text { Applications }\end{array}$ & $\begin{array}{l}\text { Optical Character } \\
\text { Recognition for } \\
\text { Marathi Text } \\
\text { Newsprint }\end{array}$ & 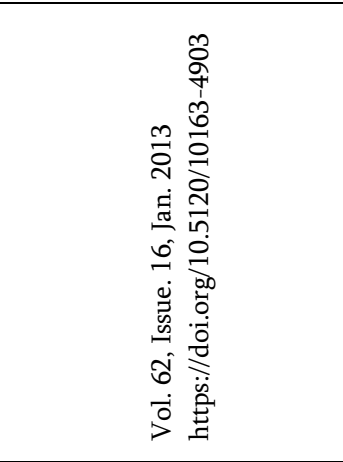 & $\begin{array}{l}\text { Worked on Marathi Script } \\
\text { Methods : Segmented using } \\
\text { bounding box. ( } 80 \text { to } 90 \% \text { ) } \\
\text { Splitted in to Upper Zone, } \\
\text { Middle Zone and Lower Zone } \\
\text { Feature Extraction: Histogram } \\
\text { / Sobel Mask for gradient } \\
\text { Classification: SVM : Feed } \\
\text { Forward Artificial Neural } \\
\text { Network }\end{array}$ \\
\hline
\end{tabular}




\begin{tabular}{|c|c|c|c|c|}
\hline $\begin{array}{l}\text { P. M. Kamble } \\
\text { and R. S. Hegadi } \\
\text { [32] }\end{array}$ & $\begin{array}{l}\text { Procedia } \\
\text { Computer } \\
\text { Science }\end{array}$ & $\begin{array}{l}\text { Handwritten Marathi } \\
\text { character recognition } \\
\text { using R-HOG } \\
\text { Feature }\end{array}$ & 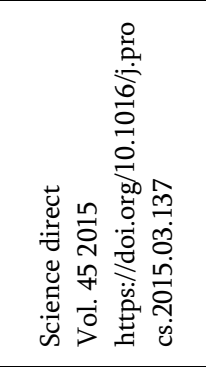 & $\begin{array}{l}\text { Worked on handwritten } \\
\text { Marathi characters } \\
\text { Methods : Segmented using } \\
\text { bounding box. } \\
\text { Classification : Support } \\
\text { Vector Machines (SVM) and } \\
\text { feed-forward Artificial Neural } \\
\text { Network }\end{array}$ \\
\hline $\begin{array}{l}\text { S. Aghav and S. } \\
\text { S. Paygude [33] }\end{array}$ & $\begin{array}{l}\text { Procedia } \\
\text { Engineering }\end{array}$ & $\begin{array}{l}\text { Computer Assisted } \\
\text { Printed Character } \\
\text { Recognition in } \\
\text { Document Based } \\
\text { Images }\end{array}$ & 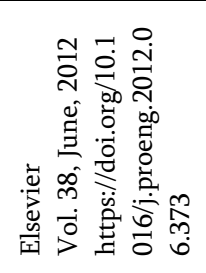 & $\begin{array}{l}\text { Worked on Printed English } \\
\text { Character } \\
\text { Methods : Segmentation } \\
\text { No Calcification Performed }\end{array}$ \\
\hline $\begin{array}{l}\text { Ahmed Mahdi } \\
\text { Obaid, Hazem } \\
\text { M. El Bakry, } \\
\text { M.A. Eldosuky, } \\
\text { A.I. Shehab [34] }\end{array}$ & $\begin{array}{l}\text { International } \\
\text { Journal of } \\
\text { Advanced } \\
\text { Research in } \\
\text { Computer } \\
\text { Science \& } \\
\text { Technology } \\
\end{array}$ & $\begin{array}{l}\text { Handwritten Text } \\
\text { Recognition System } \\
\text { Based on Neural } \\
\text { Network }\end{array}$ & 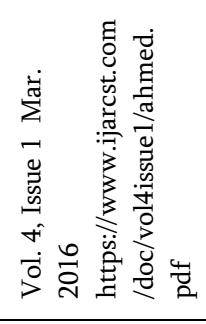 & $\begin{array}{l}\text { Worked on Handwritten } \\
\text { English Character } \\
\text { Methods : Segmented using } \\
\text { bounding box. } \\
\text { Feature Extraction: ANN }\end{array}$ \\
\hline $\begin{array}{l}\text { N. S. Panyam, V. } \\
\text { L. T.R., R. } \\
\text { Krishnan, and K. } \\
\text { R. N.V [35] }\end{array}$ & $\begin{array}{l}\text { Pattern } \\
\text { Recognition } \\
\text { Letters }\end{array}$ & $\begin{array}{l}\text { Modeling of palm leaf } \\
\text { character recognition } \\
\text { system using trans } \\
\text { form based techniques }\end{array}$ & 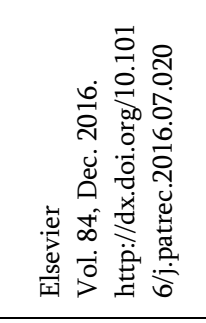 & $\begin{array}{l}\text { Worked on Handwritten } \\
\text { Telugu Character } \\
\text { Methods : co-ordinate } \\
\text { measuring machine (CMM) } \\
\text { Feature Extraction : } \\
\text { Discrete wavelet transforms } \\
\text { and fast Fourier transform }\end{array}$ \\
\hline $\begin{array}{l}\text { K. S. Varghese, } \\
\text { A. James, and S. } \\
\text { Chandran [36] }\end{array}$ & $\begin{array}{l}\text { Procedia } \\
\text { Technology, }\end{array}$ & $\begin{array}{l}\text { A Novel Tri-Stage } \\
\text { Recognition Scheme } \\
\text { for Handwritten } \\
\text { Malayalam } \\
\text { Character Recognition }\end{array}$ & 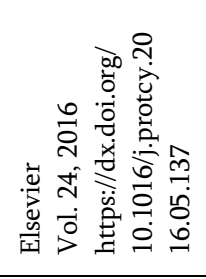 & $\begin{array}{l}\text { Worked on Handwritten } \\
\text { Malayalam Character } \\
\text { Methods : Segmentation } \\
\text { Feature Extraction : } \\
\text { Mathematical Morphology } \\
\text { Method. }\end{array}$ \\
\hline $\begin{array}{l}\text { R. Smith, D. } \\
\text { Antonova, and } \\
\text { D.-S. Lee [15] }\end{array}$ & $\begin{array}{l}\text { Proceedings of } \\
\text { the } \\
\text { International } \\
\text { Workshop on } \\
\text { Multilingual } \\
\text { OCR }\end{array}$ & $\begin{array}{l}\text { Adapting the Tesseract } \\
\text { open source OCR } \\
\text { engine for multilingual } \\
\text { OCR }\end{array}$ & 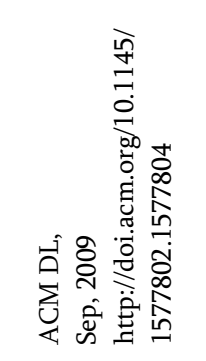 & $\begin{array}{l}\text { Worked on Printed English } \\
\text { Character } \\
\text { Methods : Tesseract Open } \\
\text { Source OCR } \\
\text { Classification : Tesseract's } \\
\text { Shape } \\
\text { Classifier }\end{array}$ \\
\hline
\end{tabular}




\begin{tabular}{|c|c|c|c|c|}
\hline $\begin{array}{l}\text { V. A. Naik and } \\
\text { A. A. Desai }[37]\end{array}$ & $\begin{array}{l}\text { 8th } \\
\text { International } \\
\text { Conference on } \\
\text { Computing, } \\
\text { Communication } \\
\text { and } \\
\text { Networking } \\
\text { Technologies }\end{array}$ & $\begin{array}{l}\text { Online handwritten } \\
\text { Gujarati character } \\
\text { recognition using } \\
\text { SVM, MLP, and K-NN }\end{array}$ & 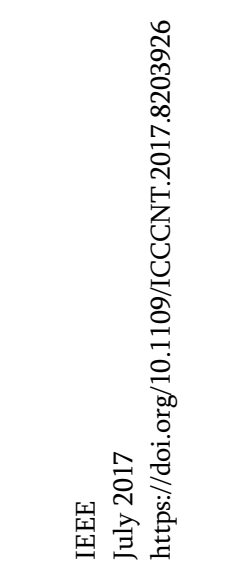 & $\begin{array}{l}\text { Worked on Handwritten } \\
\text { Gujarati Character } \\
\text { Methods : Smoothing, bilinear } \\
\text { interpolation, chain code } \\
\text { Classification : k-NN, SVM } \\
\text { and ANN classification } \\
\text { methods }\end{array}$ \\
\hline $\begin{array}{l}\text { Xiaoqing Ding, } \\
\text { Li Chen, and } \\
\text { Tao Wu [38] }\end{array}$ & $\begin{array}{l}\text { IEEE } \\
\text { Transactions on } \\
\text { Pattern } \\
\text { Analysis and } \\
\text { Machine } \\
\text { Intelligence }\end{array}$ & $\begin{array}{l}\text { Character Independent } \\
\text { Font Recognition on a } \\
\text { Single Chinese } \\
\text { Character }\end{array}$ & 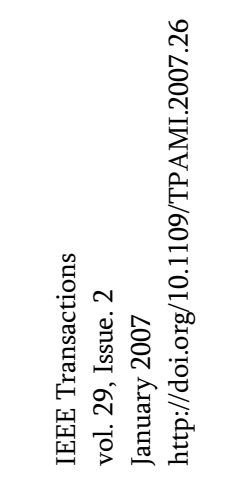 & $\begin{array}{l}\text { Worked on printed Chinese } \\
\text { Characters } \\
\text { Methods : Segmentation } \\
\text { Feature Extraction : wavelet } \\
\text { transform }\end{array}$ \\
\hline $\begin{array}{l}\text { S. Bag, G. Harit, } \\
\text { and P. } \\
\text { Bhowmick [39] }\end{array}$ & $\begin{array}{l}\text { Pattern } \\
\text { Recognition }\end{array}$ & $\begin{array}{l}\text { Recognition of Bangla } \\
\text { compound characters } \\
\text { using structural } \\
\text { decomposition }\end{array}$ & 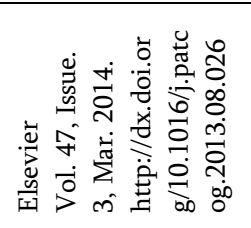 & $\begin{array}{l}\text { Worked on Bangla Characters } \\
\text { Methods : Straight Line } \\
\text { Approximation Method, } \\
\text { Classification : Quadratic } \\
\text { Discriminative Function }\end{array}$ \\
\hline A. A. Desai [40] & $\begin{array}{l}\text { Pattern } \\
\text { Recognition }\end{array}$ & $\begin{array}{l}\text { Gujarati handwritten } \\
\text { numeral optical } \\
\text { character } \\
\text { reorganization } \\
\text { through neural } \\
\text { network }\end{array}$ & 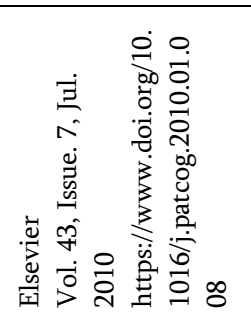 & $\begin{array}{l}\text { Worked on handwritten } \\
\text { Gujarati numbers } \\
\text { Methods : smoothing, } \\
\text { thinning, skew detection and } \\
\text { correction } \\
\text { Classification : Artificial } \\
\text { neural network }\end{array}$ \\
\hline $\begin{array}{l}\text { N. Prameela, P. } \\
\text { Anjusha, and R. } \\
\text { Karthik [41] }\end{array}$ & $\begin{array}{l}\text { International } \\
\text { Conference on } \\
\text { Electronics, } \\
\text { Communication } \\
\text { and Aerospace } \\
\text { Technology }\end{array}$ & $\begin{array}{l}\text { Off-line Telugu } \\
\text { Handwritten } \\
\text { Characters } \\
\text { Recognition using } \\
\text { optical character } \\
\text { recognition }\end{array}$ & 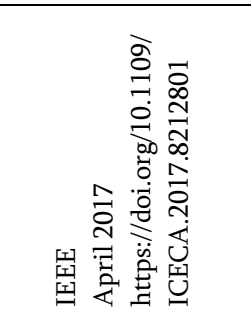 & $\begin{array}{l}\text { Worked on Hand written } \\
\text { Telugu characters } \\
\text { Methods : Euclidean } \\
\text { Distance } \\
\text { Classification : SVM and } \\
\text { Quadratic discriminate } \\
\text { Classifier }\end{array}$ \\
\hline
\end{tabular}




\begin{tabular}{|c|c|c|c|c|}
\hline $\begin{array}{l}\text { O. Surinta, M. F. } \\
\text { Karaaba, L. R. B. } \\
\text { Schomaker, and } \\
\text { M. A. Wiering } \\
\text { [42] }\end{array}$ & $\begin{array}{l}\text { Engineering } \\
\text { Applications of } \\
\text { Artificial } \\
\text { Intelligence }\end{array}$ & $\begin{array}{l}\text { Recognition of } \\
\text { handwritten } \\
\text { characters using local } \\
\text { gradient feature } \\
\text { descriptors }\end{array}$ & 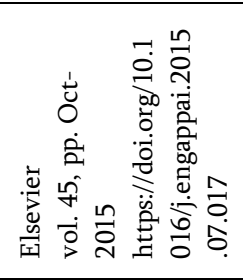 & $\begin{array}{l}\text { Worked on Thai, Bangla, and } \\
\text { Latin handwritten scripts } \\
\text { Methods : ocal gradient } \\
\text { feature descriptors } \\
\text { Classification : support vector } \\
\text { machine }\end{array}$ \\
\hline $\begin{array}{l}\text { Paul, I. J. L., } \\
\text { Sasirekha, S., } \\
\text { Vishnu, D. R., \& } \\
\text { Surya, K [10] }\end{array}$ & AIP Conference & $\begin{array}{l}\text { Recognition of } \\
\text { Handwritten Text } \\
\text { using Long Short Term } \\
\text { Memory (LSTM) } \\
\text { Recurrent Neural } \\
\text { Network (RNN) }\end{array}$ & 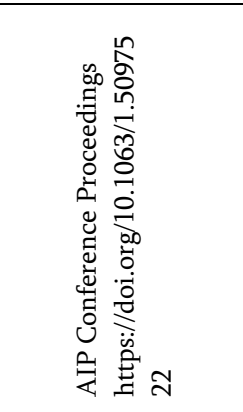 & $\begin{array}{l}\text { Handwriting recognition is a } \\
\text { technique which is used to } \\
\text { produce machine readable text } \\
\text { from a given text } \\
\text { image. } \\
\text { Methods : HMM Classification } \\
\text { and Feature Extraction : } \\
\text { Long-Term Short-Term } \\
\text { Memory Network (LSTM) }\end{array}$ \\
\hline $\begin{array}{l}\text { S. M. } \\
\text { Obaidullah, A. } \\
\text { Mondal, and K. } \\
\text { Roy [43] }\end{array}$ & $\begin{array}{l}\text { International } \\
\text { Conference on } \\
\text { Signal } \\
\text { Processing and } \\
\text { Integrated } \\
\text { Networks }\end{array}$ & $\begin{array}{l}\text { Structural feature } \\
\text { based approach for } \\
\text { script identification } \\
\text { from printed Indian } \\
\text { document }\end{array}$ & 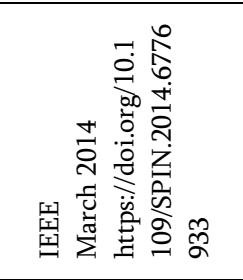 & $\begin{array}{l}\text { Worked on printed or } \\
\text { handwritten document } \\
\text { Methods : OpenCV } \\
\text { Classification : Logistic Model } \\
\text { Classifier }\end{array}$ \\
\hline $\begin{array}{l}\text { Chaudhary, G. } \\
\text { Shikkenawis, S. } \\
\text { K. Mitra, and M. } \\
\text { Goswami [44] }\end{array}$ & $\begin{array}{l}\text { Third } \\
\text { International } \\
\text { Conference on } \\
\text { Emerging } \\
\text { Applications of } \\
\text { Information } \\
\text { Technology }\end{array}$ & $\begin{array}{l}\text { Similar looking } \\
\text { Gujarati printed } \\
\text { character recognition } \\
\text { using Locality } \\
\text { Preserving Projection } \\
\text { and artificial neural } \\
\text { networks }\end{array}$ & 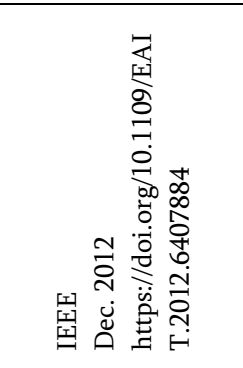 & $\begin{array}{l}\text { Worked on printed Gujarati } \\
\text { characters. } \\
\text { Methods : Locality Preserving } \\
\text { Projection(LPP) and } \\
\text { Supervised Locality Preserving } \\
\text { Projection } \\
\text { Classification : Artificial } \\
\text { Neural Networks }\end{array}$ \\
\hline $\begin{array}{l}\text { R. Sarkhel, N. } \\
\text { Das, A. Das, M. } \\
\text { Kundu, and M. } \\
\text { Nasipuri [45] }\end{array}$ & $\begin{array}{l}\text { Pattern } \\
\text { Recognition }\end{array}$ & $\begin{array}{l}\text { A multi-scale deep } \\
\text { quad tree based feature } \\
\text { extraction method for } \\
\text { the recognition of } \\
\text { isolated handwritten } \\
\text { characters of popular } \\
\text { indic scripts }\end{array}$ & 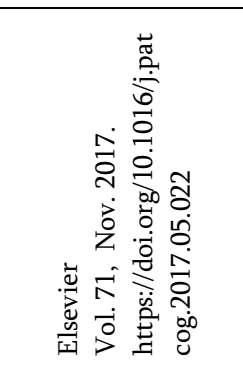 & $\begin{array}{l}\text { Worked on handwritten } \\
\text { characters of Indian scripts } \\
\text { Methods : novel multi- } \\
\text { column multi-scale } \\
\text { convolutional neural network } \\
\text { (MMCNN) } \\
\text { Feature Extraction : CNN } \\
\text { based NeF extraction method }\end{array}$ \\
\hline $\begin{array}{l}\text { J. Singh, G. } \\
\text { Singh, R. Singh, } \\
\text { and P. Singh } \\
{[46]}\end{array}$ & $\begin{array}{l}\text { Journal of King } \\
\text { Saud University } \\
\text { - Computer and } \\
\text { Information } \\
\text { Sciences }\end{array}$ & $\begin{array}{l}\text { Morphological } \\
\text { evaluation and } \\
\text { sentiment analysis of } \\
\text { Punjabi text using } \\
\text { deep learning } \\
\text { classification }\end{array}$ & 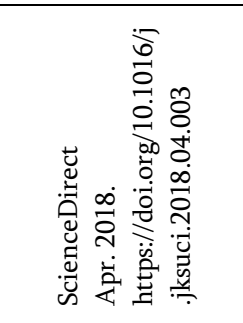 & $\begin{array}{l}\text { Worked on Morphological } \\
\text { processing of Indian languages } \\
\text { - Panjabi } \\
\text { Methods : Natural } \\
\text { Language Processing (NLP) } \\
\text { Classification : Natural } \\
\text { Language Toolkit of Python }\end{array}$ \\
\hline
\end{tabular}




\begin{tabular}{|c|c|c|c|c|}
\hline $\begin{array}{l}\text { K.S. Sesh Kumar, } \\
\text { Anoop M. } \\
\text { Namboodiri, and } \\
\text { C.V. Jawahar } \\
{[47]}\end{array}$ & $\begin{array}{l}\text { 5th Indian } \\
\text { Conference on } \\
\text { Computer } \\
\text { Vision, } \\
\text { Graphics and } \\
\text { Image } \\
\text { Processing, } \\
\text { Madurai, India }\end{array}$ & $\begin{array}{l}\text { Learning } \\
\text { Segmentation of } \\
\text { Documents with } \\
\text { Complex Scripts }\end{array}$ & 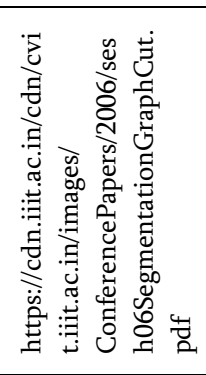 & $\begin{array}{l}\text { Segmentation algorithms has } \\
\text { designed to handle complex } \\
\text { document layouts and } \\
\text { backgrounds, while assuming } \\
\text { a simple script structure such } \\
\text { as in Roman script }\end{array}$ \\
\hline $\begin{array}{l}\text { Sachin Rawat, K. } \\
\text { S. Sesh Kumar, } \\
\text { Million } \\
\text { Meshesha, } \\
\text { Indineel Deb } \\
\text { Sikdar, A. } \\
\text { Balasubramanian } \\
\text { and C. V. } \\
\text { Jawahar [48] }\end{array}$ & $\begin{array}{l}\text { Proceedings of } \\
\text { Seventh IAPR } \\
\text { Workshop on } \\
\text { Document } \\
\text { Analysis } \\
\text { Systems, } 2006\end{array}$ & $\begin{array}{l}\text { A Semi-automatic } \\
\text { Adaptive OCR for } \\
\text { Digital Libraries }\end{array}$ & 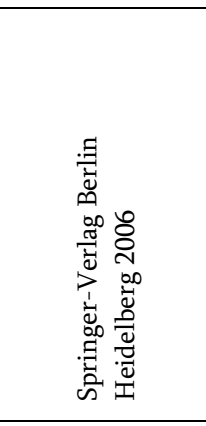 & $\begin{array}{l}\text { Semi-Automatic and adaptive } \\
\text { OCR for large collection of } \\
\text { document images, focusing on } \\
\text { applications in digital } \\
\text { libraries }\end{array}$ \\
\hline $\begin{array}{l}\text { Sameer Antani, } \\
\text { Lalitha } \\
\text { Agnihotri [49] }\end{array}$ & $\begin{array}{l}\text { Proceedings of } \\
\text { the Fifth } \\
\text { International } \\
\text { Conference on } \\
\text { Document } \\
\text { Analysis and } \\
\text { Recognition. } \\
\text { ICDAR '99 } \\
\text { (Cat. } \\
\text { No.PR00318) }\end{array}$ & $\begin{array}{l}\text { Gujarati Character } \\
\text { Recognition }\end{array}$ & 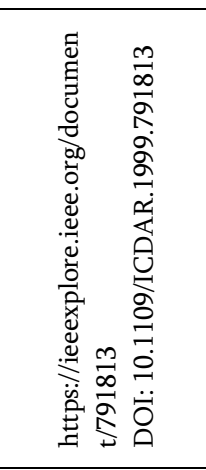 & $\begin{array}{l}\text { Methods : HMM } \\
\text { Classification : k-Nearest } \\
\text { Neighbor Classifier and } \\
\text { Minimum Hamming Distance } \\
\text { Classifier: }\end{array}$ \\
\hline $\begin{array}{l}\text { Sonika Narang, } \\
\text { M K Jindal, } \\
\text { Munish Kumar } \\
\text { [52] }\end{array}$ & $\begin{array}{l}\text { Published by } \\
\text { the Indian } \\
\text { Academy of } \\
\text { Sciences }\end{array}$ & $\begin{array}{l}\text { Devanagari ancient } \\
\text { documents recognition } \\
\text { using statistical feature } \\
\text { extraction techniques }\end{array}$ & 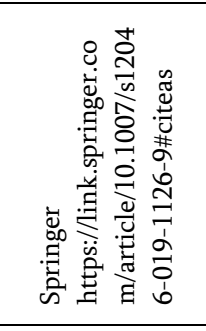 & $\begin{array}{l}\text { This system includes image } \\
\text { binarization, character } \\
\text { segmentation and recognition } \\
\text { phases. It incorporates } \\
\text { automatic recognition of } \\
\text { scanned and segmented } \\
\text { characters }\end{array}$ \\
\hline $\begin{array}{l}\text { Ahmed, S. B., } \\
\text { Naz, S., Razzak, } \\
\text { M. I., Yusof, R., } \\
\text { \& Breuel, T. M } \\
\text { [51] }\end{array}$ & $\begin{array}{l}\text { Advances in } \\
\text { Machine } \\
\text { Learning and } \\
\text { Signal } \\
\text { Processing, }\end{array}$ & $\begin{array}{l}\text { Balinese Character } \\
\text { Recognition Using } \\
\text { Bidirectional LSTM } \\
\text { Classifier }\end{array}$ & 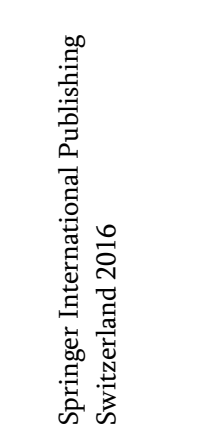 & $\begin{array}{l}\text { Indonesia's Bali Island- } \\
\text { Indonesian languages. } \\
\text { Methods : Balinese character } \\
\text { recognition Classification } \\
\text { Bidirectional LSTM }\end{array}$ \\
\hline
\end{tabular}




\section{III.DATASETS}

In general, standardised databases are required/used for testing and benchmarking different OCR algorithms in order to make meaningful comparisons [61]. The availability of a dataset with sufficient data for training and testing is always a prerequisite for high-quality research [62], [63]. Optical character recognition research is mostly focused on six different languages: English, Arabic, Indian, Chinese, Urdu, and Persian / Farsi script. MNIST, CEDAR, CENPARMI, PE92, UCOM, HCL2000, and other freely available datasets exist for these languages. The subsections that follow provide an overview of the most often used datasets for the languages described above.

In Past works of literature, Sanskrit has the most characters, with thirteen vowels and thirty-four consonants. Apart from vowels and consonants, most Indian scripts, including Devanagari, have compound (composite) characters, which are constructed by combining two or more fundamental symbols. A compound (composite) character's shape is frequently more complicated than the shape of its constituent characters.

\section{Sanskrit Devanagari Alphabet}

\section{Numerals (अंक)

$\begin{array}{lllllllllll}0 & ? & \gtrless & 3 & 8 & \varphi & \xi & 7 & 6 & 9 & \text { १० } \\ 0 & 1 & 2 & 3 & 4 & 5 & 6 & 7 & 8 & 9 & 10\end{array}$

(a)

\section{Vowels (स्वर)}

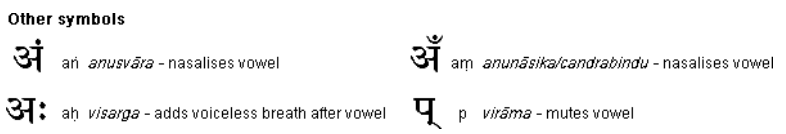

(b)

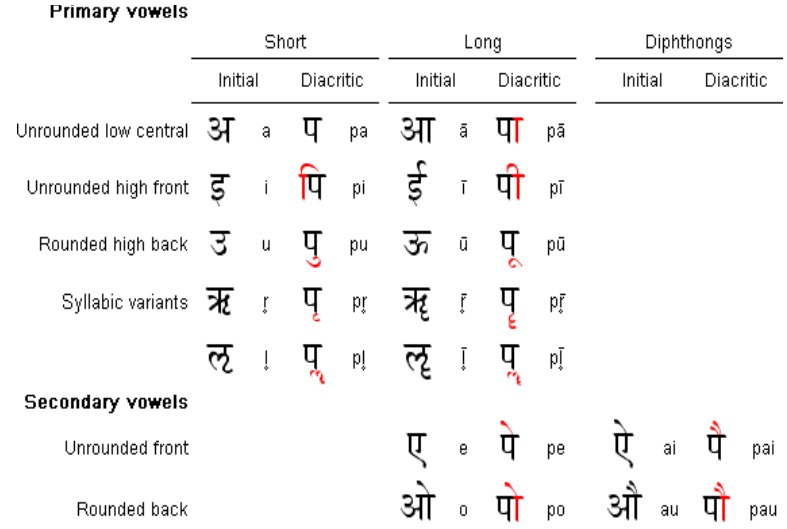

(c)

\section{Consonants (व्यंजन)}

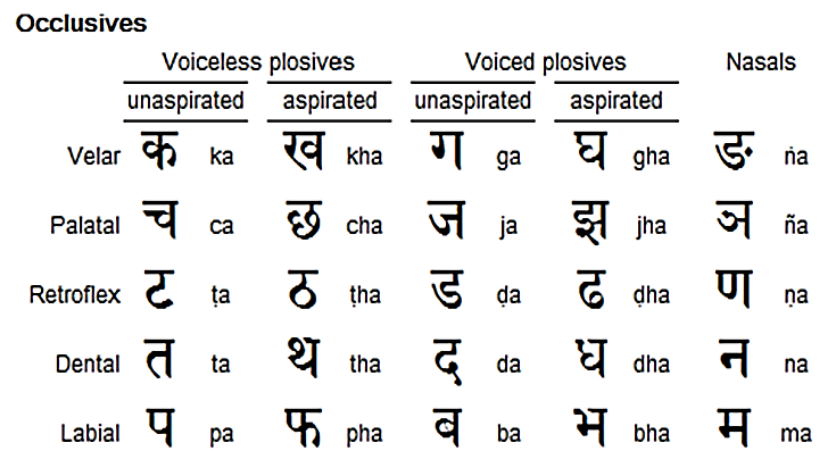

Sonorants and fricatives

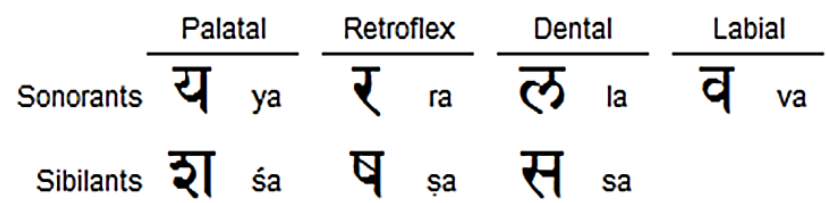

Other letters

$$
\text { ह ha ळ !a }
$$

(d)

\section{Variant Letters}

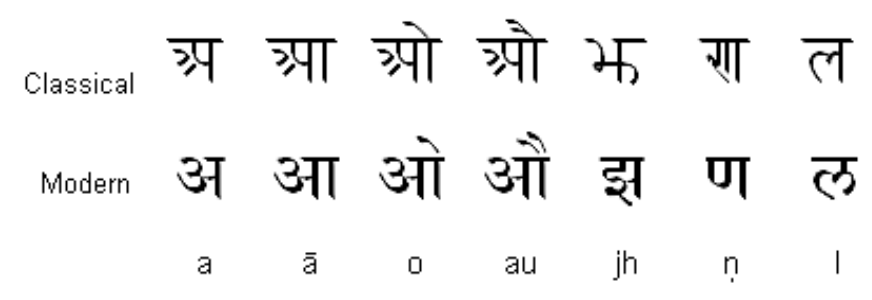

(e) 


\section{Conjunct Consonants (संयुक्तक्षर) - Ancient Worlds}

क क्रव क्र क्ण क्त्र क्र क्र क्रव क्र क्म

kka kkha kca kna kta ktya ktra ktrya ktva kna knya kma

क्य क्र क्य कु क्क क्य क्ष क्ष्म क्ष्य क्ष्व रव्य ख्व

kya kra krya kla kva kvya kṣa kṣma kșya kṣva khya khra

ग्य ग्र ग्य घ घ्य घ्म घ्य घ्र ङ ङ क्ष क्य

gya gra grya ghna ghnya ghma ghya ghra ńka nikta ńktya ńkya

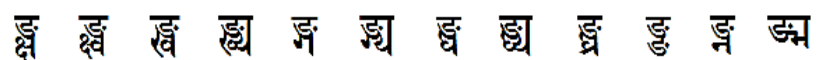

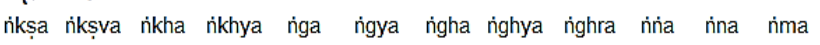

ज्य च च्छ च्छ च च्म च्य छ्य छ ज ज्ञ ज्ञ

ṅya cca ccha cchra cña cma cya chya chra ija jiha jña

इय ज्म ज्य ज्र ज्व ज्व अ्म श्य ज्छ जु कुय ट्ट

jñya jma jya jra jva ñca ñcma ñcya ñcha ñja ñjya ța

(f)

Figure 2. The Language written with the Devanagari alphabet (a,b,c,d,e,f)

As show in figure 2 Sanskrit text contains of several compound characters which are formed by different combinations of half letter and full letter consonants.

Some examples of compound characters are shown in

Fig 2. Since such compound characters are either less frequent or completely absent in Hindi text, Hindi OCRs would not be trained to segment and classify such characters correctly. Subsequently, the Hindi OCRs would display poor results in Sanskrit text.

Three Zones of Sanskrit Devanagari Script

\begin{tabular}{|l|l|l|l|}
\hline Script & Zones & Strokes & \\
\hline $\begin{array}{l}\text { Devanagari } \\
\text { सेतू }\end{array}$ & & & \\
\hline & Top & & \\
\hline
\end{tabular}

Figure 3. Horizontal zone wise basic strokes in the Devanagari word "SETU" after segmenting both words horizontally into three zones-top, middle, and bottom.

Some modifier symbols are put close to the consonants (core modifier), others are placed above the consonants (top modifier), and some are placed below (lower modifier) the consonants, according to the figure 3 [3]. Some modifiers have a core modifier and a top modifier, with the core modifier coming before or next to the consonant and the top modifier coming above it. Almost every consonant in Devanagari script has a pure version termed a half character. Conjuncts, touching characters, and fused characters are formed when a consonant in pure form contacts the following character in the script. Some of the conjuncts generated by writing pure form consonants followed by consonants are shown in Fig. 2. The header line, or shirorekha, is a horizontal line painted over the top of all letters in a word. Devanagari words can be represented as three horizontal strips or zones: a core strip, a top strip, and a bottom strip. The header line separates the middle and top zones. Fig 3 depicts a three-character term with one top modifier and one below modifier. The three strips have been delineated, as well as the header line.

\section{The framework of the OCR System.}

An OCR system usually perform the following tasks:
a) Text Digitization
b) Gray Tone to Two Tone Conversion
c) Noise Clearing
d) Text Block Identification
e) Skew Correction
f) Line and Word Detection
g) Character Segmentation 


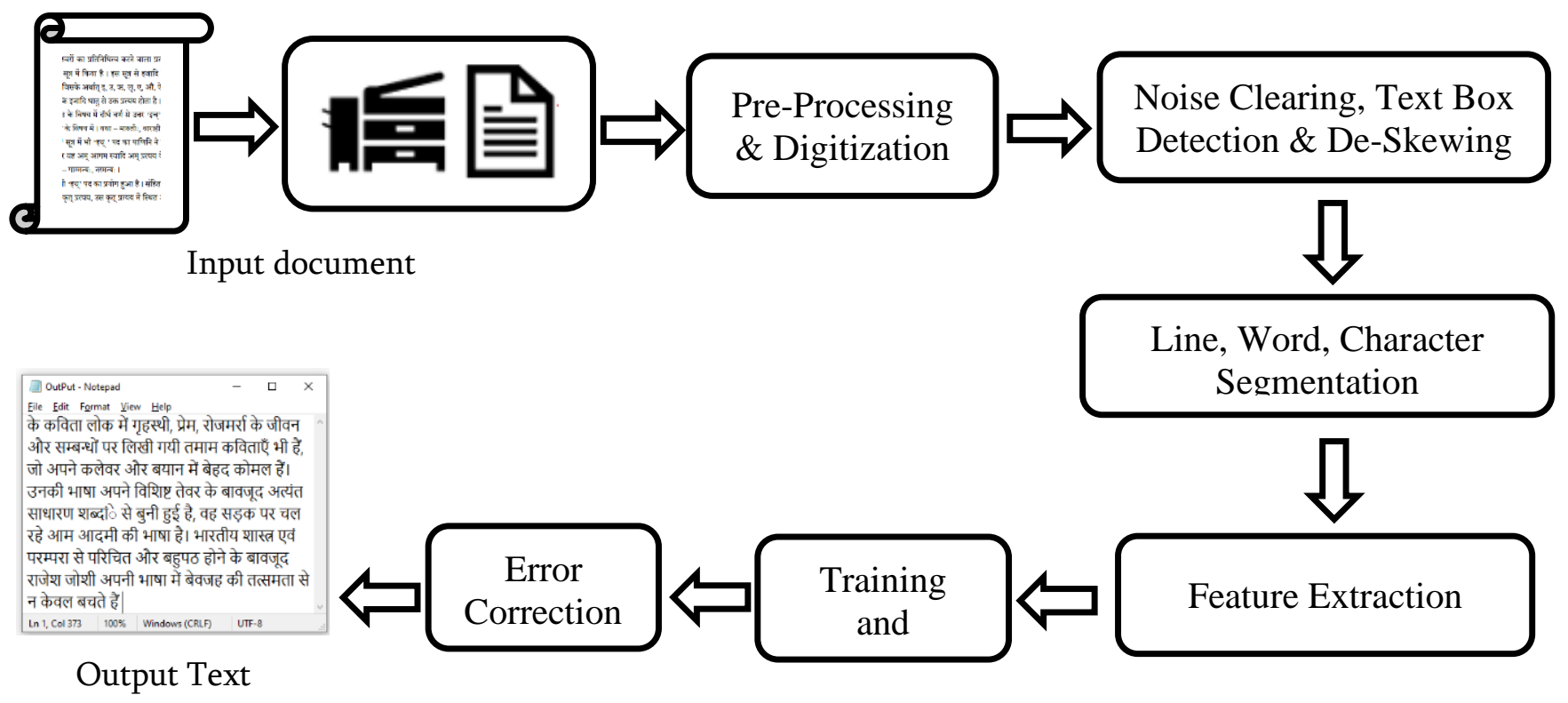

Figure 1. Flow CNN based Sanskrit OCR System

Smoothing, sharpening, binarizing the image, removing the background, and extracting the needed information all require pre-processing to make the raw data useful in the descriptive stages of character analysis. In segmentation a task that breaks down an image of an arrangement of characters into subimages of individual images by first segmenting the lines, then line segments the words, and finally from words to individual characters. The yield of the segmentation phase is confined characters of the content. The diverse strategies for feature extraction are actualized on the segregated character to get the feature vectors. These capabilities are utilized for the classification issue. At the representation step, a set of features is extracted to distinguish one image class from another. Then the classifiers that are used for

training and recognition are k-NN[4], SVM [5], Neural Network [6][7][8][9], Deep Learning (LSTM, BLSTM) [10][11].

\section{A. Image Acquisition}

Image Acquisition is the wrist and main segment in OCR. Through the filtering process, a computerized picture of unique record is caught. In OCR, optical scanners are utilized which comprise of transport component and detecting gadget that transforms optical intensity to grey levels. Documents which are printed, when performing OCR multilevel picture is changed over into bi-level highly contrasting picture. This procedure known as thresholding is performed on the scanner to spare memory space and computational exertion. The thresholding procedure is imperative as the consequences of acknowledgment are absolutely reliant on the nature of the bi-level picture. A settled limit is utilized where dim levels beneath this edge are dark and levels above are white. For high balance report with uniform foundation a pre-picked the settled limit can be adequate. Be that as it may, reports experienced by and by having rather huge range. In these cases, more advanced techniques for thresholding are required to get great outcomes. The best thresholding 
techniques fluctuate edge adjusting to nearby properties of the archive, for example, differentiation and brilliance. In any case, such strategies, as a rule, rely upon multilevel filtering of record which requires more memory and computational limit.

\section{B. Pre-Processing}

The follow-on images coming out of optical scanner may contain a specific measure of noise. Contingent upon the fortitude on the scanner and the attainment of the connected method for thresholding, the characters might be spread or broken. A portion of these deformities, which may later reason poor acknowledgment rates, can be wiped out by utilizing a pre-processor to smooth the digitized characters. The smoothing process involves both filling and fading. Filling disposes of little breaks, holes, and openings in the digitized characters, while fading lessens the width of the line. The most basic systems for smoothing, move a window over the bi-level image of the character, applying certain tenets to the substance of the window. Notwithstanding smoothing, pre-processing, as a rule, incorporates normalization. The normalization is connected to acquire characters of uniform size, inclination and turn. To have the capacity to rectify for the pivot, the angle of rotation needs to be known. [70]

\section{Skew Correction}

A few techniques have been proposed for skew recognition and alteration text images. Numerous strategies have utilized projection profiles for skew detection [71]. In general, projection profile techniques are constrained to evaluate skew point inside +10 degrees [72][73]. The second classification of techniques depends on the Hough Transform [74][75]. Hough Transform locates the best bearing of the straight lines in the documents. Another group of skew redress strategies utilizes k-closest neighbor bunching on connected components, and they endeavor to locate the best general heading of neighboring parts. Albeit numerous techniques have been proposed for skew identification and adjustment, huge numbers of them must be applied to bi-level images or just to machine printed document. A few techniques likewise involve high computational cost, for example, Hough transforms strategies. Some other techniques just manage little skew

\section{Binarization and skeletonization}

Binarization can turn into a testing work [75] under differing brightening and noise. Various elements add to muddle the thresholding process counting encompassing brightening, fluctuation of dark levels within the object and inadequate contrast. A wrong determination of edge esteem may misjudge the foundation pixel and can order it as a protest and the other way around, coming about in an overall degradation of system performance.

Skeletonization is the after effect of the thinning procedure, which peeling the form of the content until achieves most average one-pixel width. The decency of the diminishing technique is estimated by how much the skeleton separated to protect the topology of the shape with no hinder. Skeletonization is utilized as a part of the preprocessing stage for a few applications, for example, writer identification, script identification, optical character acknowledgment OCR.

\section{E. Segmentation}

Segmentation is a critical advance in a ton of complex content OCR frameworks. For the most part, the units created because of preprocessing are not the essential building squares of that specific content. So there must be a calculation to isolate littlest conceivable shapes which are utilized to build the unpredictable units. These littlest shapes are called 
sections. The extraction of these portions is fundamental for the acknowledgment module. The division is required for those contents in which the distinguishable units of Pre-handling are vast in number, and huge numbers of them share the same stroke grouping. OCR frameworks can be grouped on the bases of the division.

\section{F. Feature Extraction}

The yield of the segmentation phase is confined characterslligatures of the content. The diverse strategies for feature extraction are actualized on the segregated character \ligatures to get the feature vectors. These capabilities are utilized for the classification issue.

In the digitization of Sanskrit Manuscripts, script identification is a critical stage. Manually extracting salient elements of the given script(s) and then applying a pattern classification algorithm is a common script method of identification. However, modern machine learning approaches can automatically learn distinct features, obviating the need for manual feature extraction. The sequence-tosequence matching concept is used in sequence learning, which involves training a neural network so that the input-output pair is made up of sequences (text-lines in the case of documents).

This study's contribution to the field of Sanskrit script identification by sequence learning. The following are some of the key features

$\checkmark$ Handcrafted script-specific characteristics are not extracted. Using simply the raw pixel data, the LSTM networks can produce great results.

$\checkmark \quad$ Despite the fact that neither word or character segmentation is required (text-line extraction is

Volume 5, Issue 2, March-April -2019 | http://ijsrcseit.com required), the script identification can be done at the character level.

$\checkmark$ For sequence-to-sequence mapping, bidirectional LSTM networks are used.

\section{Statistical Features}

Statistical features are numerical measures registered over pictures or districts of pictures. They incorporate, yet are not restricted to, histograms of chain code directions, pixel densities, moments, and Fourier descriptors.

\section{Projection profile}

A projection profile is a histogram of the quantity of dark pixel esteems gathered along parallel lines taken through the Image document [76]. Projection is a condensed depiction of images since considerably useful information is reserved in the projections. Projection is not exclusive as in excess of one picture may have a similar projection. The projection profile methods have been utilized in literature for the segmentation of text lines, page layout, and estimation of Skew and in numerous applications. By just finding the number of 1 pixel in the vertical and horizontal direction the projections for horizontal and vertical projection can be easily obtained respectively.

\section{Zone-based Density Features}

Statistical features are reported to be the key features for recognition of text in several scripts. Another way to deal with discovering feature vector in OCR is utilizing density. Form the literature it is experimentally observed that an image of $32 * 32$ pixel size is adequate to extract density features. The size standardization was performed on the character picture without influencing its aspect ratio.

\section{Histogram of Oriented Gradient}

HOG descriptor has been mainly employed in the field of computer vision and object detection and 
proven to be very effective. Hog descriptor technique counts the occurrences of gradient orientation in localized portions of an image [34]. HOG descriptor is computed on a dense grid of uniformly spaced cells (splitting the original image into smaller connected zones) and uses overlapping local contrast normalization for improved accuracy [77]. In character image, HOG encodes the local shape information from regions. Size of the HOG cell influence the effectiveness of feature vector more than other attributes, If the size of the cell is large it can capture large-scale spatial information but may lose small-scale detail.

\section{Local Binary Pattern}

Local Binary Pattern (LBP), initially intended for productive texture classification gives a basic and successful path for texture recognition. The LBP has been effectively utilized as a part of texture classification, facial recognition, swarm estimation, age classification and in addition sex grouping. Two most essential properties of the LBP administrator are its heartiness against brightening changes and its computational effortlessness. Keeping in mind the end goal to make the LBP more appropriate for low determination character acknowledgment.

\section{Heuristic-Based Approaches}

Many techniques rely on the extraction of complex features and image processing techniques, as well as a variety of heuristics. This is due to the widespread idea that script-related traits must be extracted in order to reliably identify scripts. As a result, the research community has put a lot of work into finding and fine-tuning script-related characteristics. The heavy usage of heuristics to adjust feature-based approaches to the task at hand is a key concern with all feature-based methodologies. As a result, approaches and use for one script or a group of scripts may not be applicable to other scripts.

\section{Machine Learning Based Approaches}

"Machine learning is a kind of Artificial Intelligence that make computer to learn and act like people do, and enhance their learning progressively in the selfgoverning mold, by nourishing them information and data."

Many other ways extraction methods are based on modern machine learning principles, however the first uses a post-processing phase to increase accuracy, the second uses carefully picked characteristics to produce minimal recognition error, and the third uses word profile features for recognition.

Combination of RNN and Bidirectional LSTM to improve the recognition rate. first features are extracted from the image. CNN classifier is used for the sequential feature extraction from the image, and training is done

\section{G. Classification}

The task of classification expects to dole out a given object to one of the predefined classes, based on perception about it. Contingent upon the viable application, these objects can be pictures, flag waveforms or any sort of estimations that should be ordered [78]. Pattern recognition has a long history and it turned into a logical teach since the finish of the $50 \mathrm{~s}$ in the earlier century, after Frank Rosenblatt's work on perceptron [79]. A short time later, the advancement of PCs innovation has expanded the interest for down to earth uses of pattern recognition and it subsequently caused the improvement of new effective hypothetical techniques for recognition required by managing increasingly refined choice issues. These days, the overall economy is a learning economy [80], which need finding, exchanging, and better using information. Along these lines, the pattern 
recognition strategies are broadly utilized by current building applications and research about and they can be viewed as an essential part in most machine learning frameworks worked for basic leadership. Along these lines, a general pattern recognition hypothesis has been slowly created for each conceivable circumstance.

\section{LSTM}

The long-term short-term memory network (LSTM), an RNN variant in use for character recognition, has been discovered in recent research. Information is stored in a gated cell outside the regular flow of the recurrent network in LSTMs. Information can be written to, read from, or stored in a computer's memory. The cell chooses what to keep and when to open and close gates to allow reading, writing, and erasing. The LSTM design allows the network to retain data for extended periods of time while also preventing gradients from vanishing or exploding.

An LSTM network is a recurrent neural network that has LSTM cell blocks in place of our standard neural network layers. These cells have various components called the input gate, the forget gate, and the output gate shown as below.

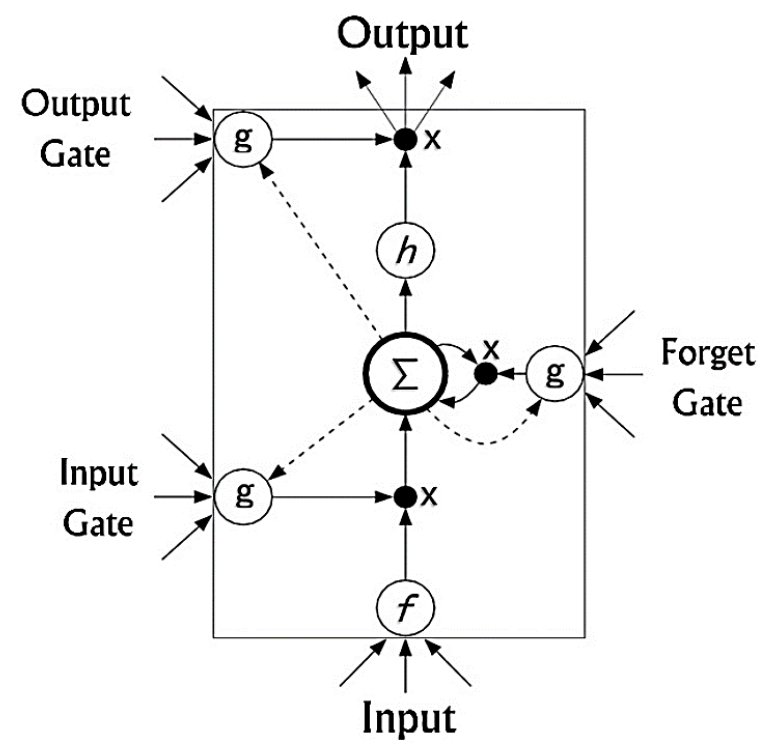

Figure 3. LSTM memory Cell - Gate functions are labeled as g, input activation as $f$, output activation as $h$, multiplication nodes as $x$ and the core node, which realizes a summation, as $\Sigma$.

The cell state, the horizontal line at the top of the picture, is crucial to LSTMs. The cell's status is similar to that of a conveyor belt. With only a few modest linear interactions, it runs the length of the chain. It is relatively easy for information to move unaltered. The LSTM may delete or add information to the cell state, which is carefully controlled by structures called gates. Gates are a mechanism to selectively allow information to pass through. A sigmoid neural net layer and a point wise multiplication operation make them up.

\section{BLSTM}

In Bidirectional LSTM network (which can be a single layer or multilayer with subsampling), the data sequence is processed by two identical hidden layer(s). One layer or one set of multiple layers process the data in the forward direction (left-toright in case of a text-line) and the other identical layer or set of multiple layers process the data in the reverse direction (right-to-left in case of a text-line).

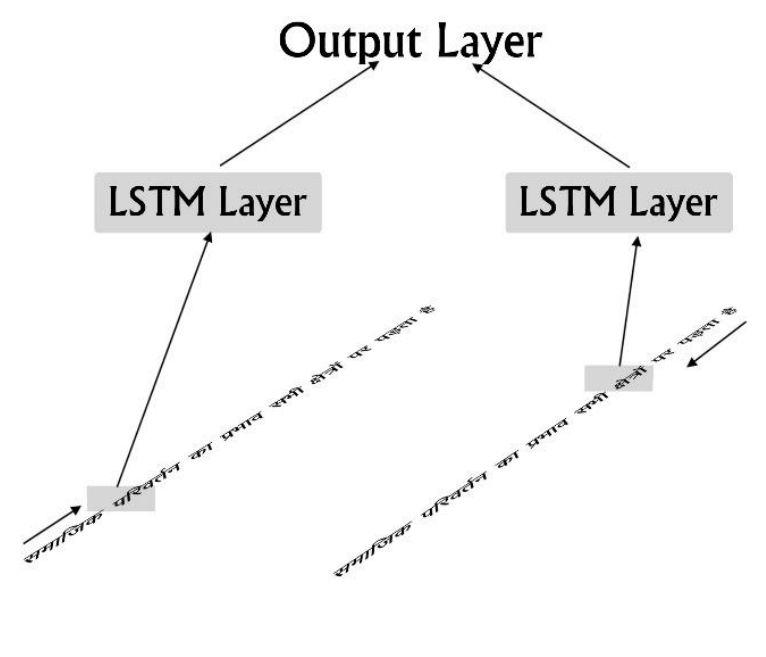




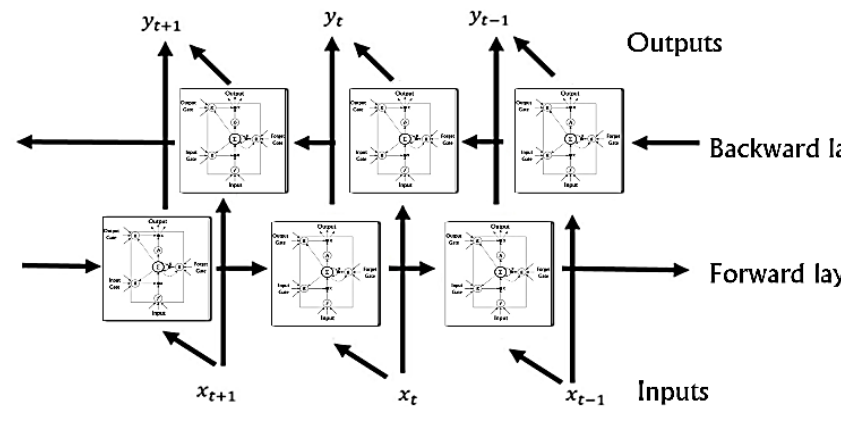

Figure 4. Bidirectional Recurrent Neural Network Layer

It is advantageous to have access to both future and previous context for many sequences labelling tasks. For example, while identifying a printed letter, it is useful to know the letters that come after it as well as those that come before it. However, because ordinary RNNs analyse sequences in chronological order, they disregard future context. The employment of a bidirectional LSTM to gain access to both future and past context might be beneficial.

A more elegant method is provided by bidirectional recurrent neural networks (BRNN). BRNNs work by presenting each training sequence forwards and backwards to two different recurrent hidden layers, both of which are connected to the same output layer. This structure gives entire past and future context to the output layer for every point in the input sequence without displacing the inputs from the relevant objectives [28].

\section{ReLU - Rectified Linear Unit}

Use of ReLU layers in combination with BLSTM layers for the challenge of continuous handwritten text recognition. We start with a conventional BLSTM neural network and stack numerous feedforward ReLU layers as well as BLSTM layers, then evaluate training behaviour and recognition accuracy.
The purpose of applying the rectifier function is to increase the non-linearity in our images. The reason we want to do is that, images are naturally nonlinear (do all negative values to 0 in the feature map).

When you look at any image, you'll find it contains a lot of non-linear features (e.g. the transition between pixels, the borders, the colors, etc.).

The rectifier serves to break up the linearity even further in order to make up for the linearity that we might impose an image when we put it through the convolution operation.

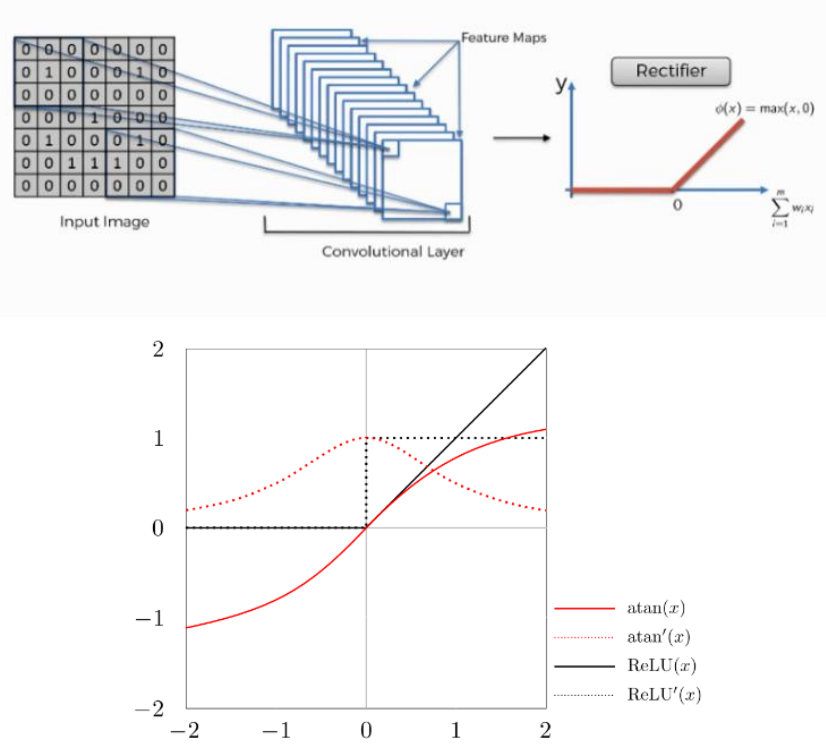

Figure 3. A plot of the atan and ReLU activation function and their derivative

\section{Performance Evaluation}

\section{A. Performance Evaluation Error}

Key concepts of measuring Optical Character Recognition output quality

(1) Error Rates and Levenshtein Distance

(2) Character Error Rate (CER)

(3) Word Error Rate (WER) 
The usual way of evaluating prediction output is with the accuracy metric, where we indicate a match (1) or a no match (0).

Here are three different types of error to consider:

$\checkmark$ Substitution error: Misspelled characters/words

$\checkmark$ Deletion error: Lost or missing characters/words

$\checkmark$ Insertion error: Incorrect inclusion of character/words

Examples of the three basic errors

\begin{tabular}{|c|c|c|}
\hline संस्कृत & संस्कृत & संस्कृत \\
\hline संस्कृन & सं कृत & संसुस्कृत \\
\hline Substitution & Deletion & Insertion \\
\hline
\end{tabular}

\section{Error Rates and Levenshtein Distance}

Error rates to determine the extent to which the OCR transcribed text and ground truth text.

Levenshtein distance is a distance metric measuring the difference between two string sequences. It is the minimum number of single-character (or word) edits (i.e., insertions, deletions, or substitutions) required to change one word (or sentence) into another.

The standard Character Error Rate (CER) and Word Error Rate (WER) as performance measures (WER).

Character Error Rate (CER) formula

$$
C E R=\frac{S+D+I}{N}
$$

\section{where:}

$\mathrm{S}=$ Number of Substitutions

$\mathrm{D}=$ Number of Deletions
$\mathrm{I}=$ Number of Insertions

$\mathrm{N}=$ Number of characters in reference text (ground truth)

\section{A good CER values}

- Good OCR accuracy: CER 1-2\% (i.e. $98-99 \%$ accurate)

- Average OCR accuracy: CER 2-10\%

- Poor OCR accuracy: CER $>10 \%$ (i.e. below $90 \%$ accurate)

WER is generally well-correlated with CER (provided error rates are not excessively high), although the absolute WER value is expected to be higher than the CER value.

\section{WER represented with this formula :}

$W E R=\frac{S_{w}+D_{w}+I_{w}}{N_{w}}$

For example:

- Ground Truth: 'संस्कृत शास्त्रों का इतिहास'

- OCR Output : 'संस्कृन शास्त्रों का इतिहास'

- From the above, the CER is $16.67 \%$, whereas the WER is $75 \%$. The WER value of $75 \%$ is clearly understood since 3 out of 4 words in the sentence were wrongly transcribed.

While CER and WER are handy, they are not bulletproof performance indicators of OCR models. This is because the quality and condition of the original documents (e.g., writing legibility, image DPI, etc.) play an equally (if not more) important role than the OCR model itself.

\section{B. Performance Evaluation Accuracy}

Evaluation of performance of model can be done using the following metrics: 
Accuracy (A) is a measure for how many correct predictions your model made for the complete test dataset:

$$
A=\frac{T P+T N}{T P+T N+F N+F P} .
$$

Recall $(\mathrm{R})$ is the fraction of images that are correctly classified over the total number of images that belong to class:

$$
\mathrm{R}=\frac{\mathrm{TP}}{\mathrm{TP}+\mathrm{FN}}
$$

Precision $(\mathrm{P})$ is the fraction of images that are correctly classified over the total number of images classified:

$$
\mathrm{P}=\frac{\mathrm{TP}}{\mathrm{TP}}+\mathrm{FP}
$$

F1 measure is a combination of Recall and Precision measures

$$
\mathrm{F} 1=2 * \frac{\mathrm{P} * \mathrm{R}}{\mathrm{P}+\mathrm{R}}
$$

Here,

$\mathrm{TP}=$ true positive (is the total number of images that can be correctly labeled as belonging to a class $\mathrm{x}$ ),

$\mathrm{FP}=$ false positive (represents the total number of images that have been incorrectly labeled as belonging to a class $\mathrm{x}$ )

$\mathrm{FN}$ = false negative (represents the total number of images that have been incorrectly labeled as not belonging to a class $\mathrm{x}$ )

$\mathrm{TN}=$ true negative (represents the total number of images that have been correctly labeled as not belonging to a class $\mathrm{x}$ ).

\section{RESEARCH TRENDS}

Characters written by various people provide a lot of intraclass heterogeneity, making it difficult for classifiers to function well. Optical character recognition research has recently shifted toward a CNN-Bidirectional LSTM (deep learning technique)
[64], [65], [60], [11] [51] with less focus on handmade features. The use of a deep learning technique enhanced classification accuracy at the expense of higher computing complexity, particularly during the training phase. In this part, we've looked at the research trends in hand character recognition during the previous three years (2017-2019).

\section{CONCLUSION}

The convolutional neural networks (CNN) introduced by LeCun [82] have revolutionized image processing and removed the manual extraction of features. CNN act directly on matrices, or even on tensors for images with three RGB color channels. Convolutional Neural Networks (CNN) are closely resembling customary ANNs in that they are included neurons that self-enhance through learning. Each neuron will, in any case, get an info and play out an activity, (for example, a scalar item taken after by a non-direct capacity) - the premise of incalculable ANNs.

The majority of published research papers recommend a solution for a different Indian language So, there is a strong need of quick and accurate character recognition for Sanskrit Manuscripts. Writing styles, distorted strokes, changing character thickness, and lighting are examples that are not included in publicly accessible datasets of Sanskrit Characters since they do not match well with real-life settings.

Researchers are increasingly employing Convolutional Neural Networks (CNN) and Bidirectional LSTM for the recognition of handwritten and machine-printed characters, according to the findings. This is because CNNBidirectional LSTM architectures are well-suited to recognition tasks with an image as input. 
The performance of CNN-Bidirectional LSTM architecture are encouraging to extend it to other Indian Language Manuscripts.

\section{REFERENCES}

[1]. D. Yadav, S. Sanchez-Cuadrado, and J. Morato, "Optical Character Recognition for Hindi Language Using a Neural-network Approach" Journal of Information Processing Systems, vol. 9, no. 1, pp. 117-140, Mar. 2013.

[2]. Ahmed Mahdi Obaid, Hazem M. El Bakry, M.A. Eldosuky, A.I. Shehab, Handwritten Text Recognition System Based on Neural Network, International Journal of Advanced Research in Computer Science \& Technology, Vol. 4, Issue 1

[3]. Jan. Agravatt, Shweta \& Goswami, Mukesh \& Agravatt, Hardik. (2015). A New Approach for Zone Identification on Printed Gujarati Text: Vertical Bar Method. International Journal of Software \& Hardware Research in Engineering. 3. 89-93.

[4]. V. A. Naik and A. A. Desai, "Online handwritten Gujarati character recognition using SVM, MLP, and $\mathrm{K}-\mathrm{NN}, "$ in 2017 8th International Conference on Computing, Communication and Networking Technologies (ICCCNT), 2017

[5]. N. Prameela, P. Anjusha, and R. Karthik, "Off-line Telugu handwritten characters recognition using optical character recognition," in 2017 IEEE International conference of Electronics, Communication and Aerospace Technology (ICECA), 2017.

[6]. A. Desai, "Gujarati handwritten numeral optical character reorganization through neural network," Pattern Recognition, vol. 43, no. 7, pp. 2582-2589, Jul. 2010.

[7]. Chaudhary, G. Shikkenawis, S. K. Mitra, and M. Goswami, "Similar looking Gujarati printed character recognition using Locality Preserving Projection and artificial neural networks," in 2012 Third International Conference on Emerging Applications of Information Technology, 2012.

[8]. Baoguang Shi, Xiang Bai, and Cong Yao. An EndtoEnd Trainable Neural Network for Image-based
Sequence Recognition and Its Application to Scene Text Recognition. IEEE transactions on pattern analysis and machine intelligence, 39(11):2298-2304, 2016.

[9]. R. Rojas, Neural Networks - A Systematic Introduction (Springer, Berlin, 1996).

[10]. Paul, I. J. L., Sasirekha, S., Vishnu, D. R., \& Surya, K. (2019). Recognition of handwritten text using long short term memory (LSTM) recurrent neural network (RNN). doi:10.1063/1.5097522

[11]. M. Schuster and K. K. Paliwal, Bidirectional recurrent neural networks, IEEE Trans. Sign. Process. 45 (1997) 2673-2681.

[12]. M. Avadesh and N. Goyal, "Optical Character Recognition for Sanskrit Using Convolution Neural Networks," 2018 13th IAPR International Workshop on Document Analysis Systems (DAS), 2018, pp. 447452, doi: 10.1109/DAS.2018.50.

[13]. R. Plamondon and S.N. Srihari. On-line and off-line handwriting recognition: A comprehensive survey. IEEE Trans. Pattern Analysis and Machine Intelligence, 22(1):63-84, 2000.।

[14]. B. B. Chaudhuri. On OCR of a printed Indian script. In Digital Document Processing: Major Directions and Recent Advances, B. B. Chaudhuri (ed.), Springer-Verlag London Ltd, pages 99-119, 2007

[15]. R. Smith, D. Antonova, and D.-S. Lee, "Adapting the Tesseract open source OCR engine for multilingual OCR," in Proceedings of the International Workshop on Multilingual OCR - MOCR '09, 2009

[16]. B. B. Chaudhuri, U. Pal. An OCR System to Read Two Indian Language Scripts: Bangla and Devanagari (Hindi). 0-8 186-7898-4/97 \$10.00 01997 IEEE.

[17]. Rahiman, M. Abdul, and M. S. Rajasree. "A detailed study and analysis of ocr research in south indian scripts." In Advances in Recent Technologies in Communication and Computing, 2009. ARTCom'09. International Conference on, pp. 31-38. IEEE, 2009.

[18]. C. V. Jawahar, M. N. S. S. K. Pavan Kumar, S. S. Ravi Kiran. A Bilingual OCR for Hindi-Telugu Documents and its Applications. ICDAR 2003, 0-7695-1960-1/03 $\$ 17.00$ (C) 2003, IEEE

[19]. Mahmud, J.U.; Raihan, M.F.; Rahman, C.M., "A complete OCR system for continuous Bengali 
characters," TENCON 2003. Conference on Convergent Technologies for the Asia-Pacific Region , vol.4, no., pp.1372,1376 Vol.4, 15-17 Oct. 2003 doi: 10.1109/TENCON.2003.1273141

[20]. Kiran R Dahake, S R Suralkar and S P Ramteke. Article: Optical Character Recognition for Marathi Text Newsprint. International Journal of Computer Applications 62(16):11-15, January 2013

[21]. Malik, S.; Khan, S.A., "Urdu online handwriting recognition," Emerging Technologies, 2005. Proceedings of the IEEE Symposium on , vol., no., pp.27,31, 18-18 Sept. 2005 doi: 10.1109/ICET.2005.1558849

[22]. Brijesh Sojitra, Vishnukumar Dhakad, "Neural Network In Character Recognition Of Gujarati Script"Journal Of Information, Knowledge And Research In Computer Engineering, ISSN: 09756760, Volume - 02, Issue - 02, Pp.269-272

[23]. Vijaykumar, B.; Ramakrishnan, A.G., "Radial basis function and subspace approach for printed Kannada text recognition," Acoustics, Speech, and Signal Processing, 2004. Proceedings. (ICASSP '04). IEEE International Conference on , vol.5, no., pp.V,321-4 vol.5, 17-21 May 2004 doi: 10.1109/ICASSP.2004.1327112

[24]. Rajput, G.G.; Horakeri, R., "Shape descriptors based handwritten character recognition engine with application to Kannada characters," Computer and Communication Technology (ICCCT), 2011 2nd International Conference on , vol., no., pp.135,141, 15-17 Sept. 2011 doi: 10.1109/ICCCT.2011.6075175

[25]. Anil R, Arjun Pradeep, Midhun E M, Manjusha K, "Malayalam Character Recognition using Singular Value Decomposition", International Journal of Computer Applications, ISSN:0975 - 8887, Volume 92 - No.12, April 2014, pp-6-11.

[26]. R. Maalej and M. Kherallah, "Convolutional Neural Network and BLSTM for Offline Arabic Handwriting Recognition," 2018 International Arab Conference on Information Technology (ACIT), Werdanye, Lebanon, 2018, pp. 1-6

[27]. P. M. Kamble and R. S. Hegadi, "Handwritten Marathi Character Recognition Using R-HOG
Feature," Procedia Computer Science, vol. 45, pp. 266-274, 2015.

[28]. Yoon, Byung-Jun. "Hidden Markov Models and their Applications in Biological Sequence Analysis." Current genomics vol. 10,6 (2009): 402-15. doi:10.2174/138920209789177575

[29]. D. Yadav, S. Sanchez-Cuadrado, and J. Morato, "Optical Character Recognition for Hindi Language Using a Neural-network Approach" Journal of Information Processing Systems, vol. 9, no. 1, pp. 117-140, Mar. 2013.

[30]. Agravatt, Shweta \& Goswami, Mukesh \& Agravatt, Hardik. (2015). A New Approach for Zone Identification on Printed Gujarati Text: Vertical Bar Method. International Journal of Software \& Hardware Research in Engineering. 3. 89-93.

[31]. K. R.Dahake, S. R. Suralkar, and S. P. Ramteke, "Optical Character Recognition for Marathi Text Newsprint," International Journal of Computer Applications, vol. 62, no. 16, pp. 11-15, Jan. 2013.

[32]. P. M. Kamble and R. S. Hegadi, "Handwritten Marathi Character Recognition Using R-HOG Feature," Procedia Computer Science, vol. 45, pp. 266-274, 2015.

[33]. S. Aghav and S. S. Paygude, "Computer Assisted Printed Character Recognition in Document Based Images," Procedia Engineering, vol. 38, pp. 32223227, 2012.

[34]. Ahmed Mahdi Obaid, Hazem M. El Bakry, M.A. Eldosuky, A.I. Shehab, Handwritten Text Recognition System Based on Neural Network, International Journal of Advanced Research inComputer Science \& Technology, Vol. 4, Issue 1 (Jan. - Mar. 2016) pp 72-77

[35]. N. S. Panyam, V. L. T.R., R. Krishnan, and K. R. N.V., "Modeling of palm leaf character recognition system using transform based techniques," Pattern Recognition Letters, vol. 84, pp. 29-34, Dec. 2016.

[36]. K. S. Varghese, A. James, and S. Chandran, "A Novel Tri-Stage Recognition Scheme for Handwritten Malayalam Character Recognition," Procedia Technology, vol. 24, pp. 1333-1340, 2016.

[37]. V. A. Naik and A. A. Desai, "Online handwritten Gujarati character recognition using SVM, MLP, and 
$\mathrm{K}-\mathrm{NN}$," in 2017 8th International Conference on Computing, Communication and Networking Technologies (ICCCNT), 2017.

[38]. Xiaoqing Ding, Li Chen, and Tao Wu, "Character Independent Font Recognition on a Single Chinese Character," IEEE Transactions on Pattern Analysis and Machine Intelligence, vol. 29, no. 2, pp. 195-204, Feb. 2007

[39]. S. Bag, G. Harit, and P. Bhowmick, "Recognition of Bangla compound characters using structural decomposition," Pattern Recognition, vol. 47, no. 3, pp. 1187-1201, Mar. 2014.

[40]. A. A. Desai, "Gujarati handwritten numeral optical character reorganization through neural network," Pattern Recognition, vol. 43, no. 7, pp. 2582-2589, Jul. 2010.

[41]. N. Prameela, P. Anjusha, and R. Karthik, "Off-line Telugu handwritten characters recognition using optical character recognition," in 2017 International conference of Electronics, Communication and Aerospace Technology (ICECA), 2017.

[42]. O. Surinta, M. F. Karaaba, L. R. B. Schomaker, and M.

A. Wiering, "Recognition of handwritten characters using local gradient feature descriptors," Engineering Applications of Artificial Intelligence, vol. 45, pp. 405-414, Oct. 2015.

[43]. S. M. Obaidullah, A. Mondal, and K. Roy, "Structural feature based approach for script identification from printed Indian document," in 2014 International Conference on Signal Processing and Integrated Networks (SPIN), 2014.

[44]. Chaudhary, G. Shikkenawis, S. K. Mitra, and M. Goswami, "Similar looking Gujarati printed character recognition using Locality Preserving Projection and artificial neural networks," in 2012 Third International Conference on Emerging Applications of Information Technology, 2012.

[45]. R. Sarkhel, N. Das, A. Das, M. Kundu, and M. Nasipuri, "A multi-scale deep quad tree based feature extraction method for the recognition of isolated handwritten characters of popular indic scripts," Pattern Recognition, vol. 71, pp. 78-93, Nov. 2017.

[46]. J. Singh, G. Singh, R. Singh, and P. Singh, "Morphological evaluation and sentiment analysis of
Punjabi text using deep learning classification," Journal of King Saud University - Computer and Information Sciences, Apr. 2018.

[47]. K.S.Sesh Kumar, Anoop M. Namboodiri and C. V. Jawahar - Learning Segmentation of Documents with Complex Scripts, 5th Indian Conference on Computer Vision, Graphics and Image Processing, Madurai, India LNCS 4338 pp.749-760, 2006.

[48]. Sachin Rawat, K. S. Sesh Kumar, Million Meshesha, Indineel Deb Sikdar, A. Balasubramanian and C. V. Jawahar - A Semi-Automatic Adaptive OCR for Digital Libraries, Proceedings of Seventh IAPR Workshop on Document Analysis Systems, 2006 (LNCS 3872), pp 13-24

[49]. Sameer Antani and Lalitha Agnihotri. 1999. Gujarati Character Recognition. In Proceedings of the Fifth International Conference on Document Analysis and Recognition (ICDAR '99). IEEE Computer Society, Washington, DC, USA

[50]. Narang, S., Jindal, M.K. \& Kumar, M. Sādhanā (2019) 44: 141. https://doi.org/10.1007/s12046-019-1126-9

[51]. Ahmed, S. B., Naz, S., Razzak, M. I., Yusof, R., \& Breuel, T. M. (2016). Balinese Character Recognition Using Bidirectional LSTM Classifier. Advances in Machine Learning and Signal Processing, 201-211. doi:10.1007/978-3-319-32213-1_18

[52]. K. R.Dahake, S. R. Suralkar, and S. P. Ramteke, "Optical Character Recognition for Marathi Text Newsprint," International Journal of Computer Applications, vol. 62, no. 16, pp. 11-15, Jan. 2013.

[53]. S. Aghav and S. S. Paygude, "Computer Assisted Printed Character Recognition in Document Based Images," Procedia Engineering, vol. 38, pp. 32223227, 2012.- Mar. 2016) pp 72-77

[54]. K. S. Varghese, A. James, and S. Chandran, "A Novel Tri-Stage Recognition Scheme for Handwritten Malayalam Character Recognition" Procedia Technology, vol. 24, pp. 1333-1340, 2016.

[55]. J. Singh, G. Singh, R. Singh, and P. Singh, "Morphological evaluation and sentiment analysis of Punjabi text using deep learning classification," Journal of King Saud University - Computer and Information Sciences, Apr. 2018. 
[56]. K.S.Sesh Kumar, Anoop M. Namboodiri and C. V. Jawahar - Learning Segmentation of Documents with Complex Scripts, 5th Indian Conference on Computer Vision, Graphics and Image Processing, Madurai, India LNCS 4338 pp.749-760, 2006.

[57]. Bansal, Veena \& Sinha, R.M.K.. (2000). Integrating knowledge sources in Devanagari text recognition system. Systems, Man and Cybernetics, Part A: Systems and Humans, IEEE Transactions on. 30. 500 505. 10.1109/3468.852443.

[58]. Dutta, K., Krishnan, P., Mathew, M., \& Jawahar, C.V. (2018). Offline Handwriting Recognition on Devanagari Using a New Benchmark Dataset. 2018 13th IAPR International Workshop on Document Analysis Systems (DAS), 25-30.

[59]. Holley, Rose. (2009). How good can it get? Analysing and improving OCR accuracy in large scale historic newspaper digitisation programs. D-Lib Magazine: The Magazine of the Digital Library Forum. 15.

[60]. Saluja, R., Adiga, D., Chaudhuri, P., Ramakrishnan, G., \& Carman, M.J. (2017). Error Detection and Corrections in Indic OCR Using LSTMs. 2017 14th IAPR International Conference on Document Analysis and Recognition (ICDAR), 01, 17-22.

[61]. R. A. Khan, A. Crenn, A. Meyer, and S. Bouakaz, "A novel database of children's spontaneous facial expressions (LIRIS-CSE)," Image Vis. Comput., vols. 83-84, pp. 61-69, Mar. 2019

[62]. R. Hussain, A. Raza, I. Siddiqi, K. Khurshid, and C. Djeddi, "A comprehensive survey of handwritten document benchmarks: Structure, usage and evaluation," EURASIP J. Image Video Process., vol. 2015, no. 1, p. 46, Dec. 2015.

[63]. R. A. Khan, É. Dinet, and H. Konik, "Visual attention: Effects of blur," in Proc. IEEE Int. Conf. Image Process., Sep. 2011, pp. 3289-3292.

[64]. S. Naz, A. I. Umar, R. Ahmad, I. Siddiqi, S. B. Ahmed, M. I. Razzak, and F. Shafait, "Urdu nastaliq recognition using convolutional-recursive deep learning," Neurocomputing, vol. 243, pp. 80-87, Jun. 2017.

[65]. M. Al-Ayyoub, A. Nuseir, K. Alsmearat, Y. Jararweh, and B. Gupta, "Deep learning for Arabic NLP: A survey," J. Comput. Sci., vol. 26, pp. 522-531, May 2018.

[66]. S. Long, X. He, and C. Yao, "Scene text detection and recognition : The deep learning era," 2018, arXiv:1811.04256. [Online]. Available: https://arxiv.org/abs/1811.04256

[67]. C. Szegedy, W. Liu, Y. Jia, P. Sermanet, S. Reed, D. Anguelov, D. Erhan, V. Vanhoucke, and A. Rabinovich, "Going deeper with convolutions," in Proc. IEEE Conf. Comput. Vis. Pattern Recognit. (CVPR), Jun. 2015, pp. 1-9.

[68]. Krizhevsky, I. Sutskever, and G. E. Hinton, "ImageNet classifi cation with deep convolutional neural networks," in Proc. 25th Int. Conf. Neural Inf. Process. Syst. (NIPS), vol. 1. Red Hook, NY, USA: Curran Associates, 2012, pp. 1097-1105. [Online]. Available:

http://dl.acm.org/citation.cfm?id=2999134.2999257

[69]. K. He, X. Zhang, S. Ren, and J. Sun, "Deep residual learning for image recognition," in Proc. IEEE Conf. Comput. Vis. Pattern Recognit. (CVPR), Jun. 2016, pp. 770-778.

[70]. A. Chaudhuri et al., Optical Character Recognition Systems for Different Languages with Soft Computing, Studies in Fuzziness and Soft Computing 352, Springer International Publishing AG 2017DOI 10.1007/978-3-319-50252-6_2

[71]. X. Jiang, H. Bunke, and D. Widmer-Kljajo, Proc. of the Fifth International Conference on Document Analysis and Recognition, Bangalore, pp.629-632, 1999.

[72]. J. Kumar, T. Kasar, and A. G. Ramakrishnan, IEEE TENCON 2007, pp.1-4, 2007

[73]. S. Srihari and V.Govindaraju, Machine Vision and Applications, 2:141-153, 1989.

[74]. C. Singha, N. Bhatiab, and A. Kaurc, Pattern Recognition, Vol. 41, pp. 3528-3546, 2008.

[75]. Gatos, B., Ntirogiannis, K., Perantonis S.J. Improved document image binarization by using a combination of multiple binarization techniques and adapted edge information. In Proceedings of 19th International Conference on Pattern Recognition (ICPR), pp. 1-4 (2008). 
[76]. R. Kasturi, L. O. Gorman, and V. Govindaraju, "Document image analysis: A primer," Sadhana Part 1, vol. 27, pp. 3-22, 2002.

[77]. HOG feature extraction ,extractHOGFeatures, Description of HOG descriptor. Matlab function command description, Link:https://in.mathworks.com/help/vision/ref/extrac thogfeature s.html?s-tid=srchtitle.

[78]. Rosenblatt, F.: The Perceptron: A probabilistic model or information storageand organization in the brain. Psychological Review 65, 386-408 (1958)

[79]. Drucker, P.F.: The age of discontinuity; guidelines to our changing society, 1st edn. Harper and Row New York (1969).

[80]. Jain, A.K., Duin, R.P.W., Mao, J.: Statistical pattern recognition: A review. IEEE Trans. Pattern Anal. Mach. Intell. 22(1) (2000) 4-37.

[81]. Fukunaga, K.: Introduction to Statistical Pattern Recognition. Academic Press, 2nd edition (1990).

[82]. Altwaijry, Najwa; Al-Turaiki, Isra (2020). Arabic handwriting recognition system using convolutional neural network. Neural Computing and Applications doi:10.1007/s00521-020-05070-8

[83]. LeCun Y., Jackel L., Boser B., Denker J., Graf H., Guyon I., Henderson D., Howard R., and Hubbard W. Handwritten digit recognition : Applications of neural networks chipsand automatic learning. Proceedings of the IEEE, 86(11):2278-2324, 1998.

\section{Cite this Article}

Bhavesh Kataria, Dr. Harikrishna B. Jethva, "CNNBidirectional LSTM Based Optical Character Recognition of Sanskrit Manuscripts : A Comprehensive Systematic Literature Review", International Journal of Scientific Research in Computer Science, Engineering and Information Technology (IJSRCSEIT), ISSN : 2456-3307, Volume 5 Issue 2, pp. 1362-1383, March-April 2019. Available at doi : https://doi.org/10.32628/CSEIT2064126

Journal URL : https://ijsrcseit.com/CSEIT2064126 